\title{
METODOLOGIA CIENTÍFICA EM CURSOS DE PÓS-GRADUAÇÃO EAD: IMPLICAÇÕES NO DESENVOLVIMENTO DO TRABALHO DE CONCLUSÃO DE CURSO
}

\author{
SÃO PAULO/SP JUNHO/2018 \\ Nayara Amaral Lima de Valois - EaD Laureate - nayaravalois@gmail.com \\ Tipo: Relato de Experiência Inovadora (EI) \\ Categoria: Métodos e Tecnologias \\ Setor Educacional: EDUCAÇÃO SUPERIOR
}

\begin{abstract}
RESUMO
O artigo traz um estudo resumido da experiencia de dois anos como docente da disciplina Metodologia Científica, oferecida para todos os cursos de pós-graduação 100\% online em IES privada. O objetivo principal é discutir sobre as implicações da formação deficiente nessa disciplina, principalmente o impacto no resultado das atividades avaliativas e para o desenvolvimento do trabalho de conclusão de curso (TCC). Para alcançar os objetivos, utilizou-se uma base de dados obtida de uma faculdade sobre o aproveitamento dos estudantes na disciplina de metodologia científica, fazendo um estudo analítico-indutivo e comparativo sobre o desempenho dos estudantes aprovados na finalização do TCC. Verifica-se que a maioria dos estudantes desconhece as normas envolvidas na elaboração de textos científicos, tais como: desenvolvimento e estrutura do trabalho, padrões de redação, procedimentos para fazer pesquisas bibliográficas, seleção e organização da leitura das obras, construção de citações diretas e indiretas; e essa deficiência prejudica a qualidade do trabalho final para conclusão do curso. Espera-se que a discussão a partir desse estudo, alavanque a necessidade de melhorias na estrutura de oferta da disciplina metodologia científica para os cursos de pósgraduação online. Este estudo também visa dar ênfase na necessidade de aumento da qualidade dos trabalhos de conclusão de curso e no maior interesse dos professores que atuam como orientadores de TCC nesta modalidade de ensino. O aporte teórico utilizado para o estudo está embasado em: Maia (2008); Leite e Andrade (2015); dentre outros.
\end{abstract}

Palavras-chave: Metodologia Científica, Deficiência na aprendizagem, Implicações, Trabalho de Conclusão de Curso 


\section{Introdução}

Metodologia Científica (MC) é uma disciplina do ensino superior que estuda os métodos e técnicas utilizados como instrumentos para o desenvolvimento de pesquisas científicas. Essa disciplina é fundamental em toda a vida acadêmica e profissional e possui, em seu conteúdo, o objetivo de auxiliar estudantes e pesquisadores a expor o conhecimento adquirido em suas pesquisas acadêmicas e científicas.

Atingir o objetivo da disciplina Metodologia Científica com os estudantes é desafiador para qualquer curso superior. Segundo Maia (2008), "a passagem do Ensino Básico para o Superior deveria ser tratada com maior cuidado", visto que a escrita de textos acadêmicos é mais exigida para esses estudantes. O cenário educacional atual exige dos docentes um esforço maior na exposição e prática dos conceitos na disciplina MC devido aos problemas estruturais dos sistemas de ensino público e privado no Brasil, principalmente no que tange à leitura e escrita de textos que exponham as ideias e a discussão de resultados (MAIA, 2008).

Especialmente para cursos superiores na modalidade de Educação a Distância (EaD), em que são necessários a abordagem dos assuntos utilizando metodologias ativas, sala de aula invertida ou outros recursos didáticos online, a disciplina MC traz desafios peculiares para os docentes. Um dos objetivos da disciplina MC é habilitar os estudantes para que utilizem os métodos e técnicas de pesquisa na elaboração de um trabalho científico, como o Trabalho de Conclusão de Curso (TCC), por exemplo. Outros objetivos comuns na disciplina MC dos cursos superiores são: debater os conceitos sobre a ciência e os tipos de conhecimento; compreender os princípios e normas científicas (padrão ABNT) utilizadas para redigir e apresentar trabalhos acadêmicos científicos; apresentar ferramentas para realização de pesquisa científica; e desenvolver as etapas de elaboração de projetos de pesquisa (OLIVEIRA E VALENÇA, 2015).

Cada um desses objetivos pode ser considerado um desafio em particular, principalmente quando há estudantes que iniciam um curso superior sem possuir nenhum conhecimento sobre o assunto. Para estudantes de pós-graduação, assume-se que haja um conhecimento prévio, pelo menos básico, na utilização de normas e na apresentação de trabalhos acadêmicos. Contudo, o fato é que são muitas as dificuldades apresentadas pelos estudantes no desenvolvimento do Trabalho de Conclusão de Curso, mesmo aqueles de cursos de pós-graduação. Nesse contexto, apresenta-se a relevância desse relato de experiência, como meio de abordar e discutir a importância do ensino criterioso dessa disciplina de metodologia científica na formação dos estudantes dos cursos superiores em EaD. 
Esse estudo possui o objetivo principal de discutir sobre as implicações da formação deficiente nessa disciplina, especialmente para o desenvolvimento do trabalho de conclusão de curso (TCC) e apresentar o impacto positivo no resultado de aprovação final, devido a alterações aplicadas no formato das atividades avaliativas da disciplina, ao longo de dois anos consecutivos de ensino em Instituição de Ensino Superior (IES) privada.

\section{Metodologia Científica como base para o conhecimento}

Severino (2000, p.18) define Metodologia como [...] "um instrumental extremamente útil e seguro para a gestação de uma postura amadurecida frente aos problemas científicos, políticos e filosóficos que nossa educação universitária enfrenta".

O autor ainda destaca que a metodologia "[...] são instrumentos operacionais, sejam eles técnicos ou lógicos, mediante os quais os estudantes podem conseguir maior aprofundamento na ciência, nas artes ou na filosofia, o que, afinal, é o objetivo intrínseco do ensino e da aprendizagem universitária" (SEVERINO, 2000, p.19).

No mundo acadêmico, todas as descobertas e invenções devem ser respaldadas por uma pesquisa científica a partir da qual se contribui para a ciência. A pesquisa científica, do mesmo modo, deve ser respaldada por métodos científicos que representam a forma de pensar do pesquisador, sendo por meio dessa metodologia que os problemas são estudados, explicados e solucionados.

Dessa forma, entende-se que a pesquisa científica está alicerçada na metodologia científica, e possui três dimensões, segundo o Severino (2000):

\footnotetext{
"De um lado, tem uma dimensão epistemológica: a perspectiva do conhecimento. Só se conhece construindo o saber, ou seja, praticando a significação dos objetos [...] assume ainda uma dimensão pedagógica: a perspectiva decorrente de sua relação com a aprendizagem. Ela é mediação necessária e eficaz para o processo de ensino/aprendizagem. Só se aprende e só se ensina pela efetiva prática da pesquisa. Mas ela tem ainda uma dimensão social: a perspectiva da extensão [...]". (SEVERINO, 2000, p. 26, grifo do autor).
}

Essa postura de estudo mais aprofundado, com a utilização de pesquisa e de critérios mais disciplinados e orientados à solução de problemas é o que se espera dos estudantes do ensino superior. A pesquisa deve assumir um papel mais importante para o estudante de um curso de pós-graduação, por exemplo, pois ele "fará uso da pesquisa para aprimorar, pôr em prática e construir conhecimento de maneira significativa", de acordo com Oliveira e Valença (2015). 


\section{A disciplina de Metodologia Científica nos cursos de pós-graduação EaD: relato da experiência}

Segundo Maia (2008), a disciplina Metodologia Científica promove o desenvolvimento do pensamento crítico-reflexivo dos estudantes, o que é primordial para auxiliar na melhoria da produtividade e da qualidade das produções de textos científicos.

Tomando como norteador essas afirmações, pôde-se avaliar o plano de aulas da disciplina MC e verificar a necessidade de melhoria na disciplina oferecida para os cursos de pós-graduação $100 \%$ online em uma IES privada.

Aparente semelhança com um estudo realizado por Leite e Andrade (2015), este estudo se apresentou nas abordagens e questionamentos dos estudantes durante o ensino dos tópicos da disciplina de metodologia científica dos cursos de pós-graduação da IES estudada. A maioria mostrou dificuldades nas respostas das atividades propostas e na construção do texto acadêmico-científico que deve compor o projeto de pesquisa para o TCC, quando posteriormente matriculados. Também postaram muitas dúvidas referentes à formatação do texto, normas $A B N T$, métodos de pesquisa e formas de publicação de trabalhos científicos.

Com base nas dificuldades apresentadas pelos estudantes que cursaram a disciplina MC nos anos 2016 e 2017, decidiu-se junto à coordenação pedagógica uma alteração na condução das aulas síncronas e na proposição de um novo tipo de atividade dissertativa (atividade 2 da disciplina).

\subsection{Estrutura da disciplina}

A disciplina MC é composta dos seguintes itens: três unidades de estudo alicerçadas por apresentação, contextualização, indicação de leitura, case-report e vídeo-case, materiais complementares, atividades avaliativas e aulas online em plataforma do Ambiente Virtual de Aprendizagem (AVA). As atividades avaliativas são propostas por um fórum avaliativo, uma questão dissertativa e questões objetivas.

Apesar de todos os itens apresentarem consonância com a ementa da disciplina, ainda assim da forma que estavam definidas, não atendiam completamente ao objetivo da disciplina de habilitar os estudantes para a construção do TCC. Na segunda atividade era proposta uma questão dissertativa abordando um dos tópicos da ementa da disciplina e apresentado em discussão na aula online. Contudo, não havia nenhuma menção ao desenvolvimento do trabalho de conclusão, o que causava dúvidas nos 
estudantes que logo em seguida deveriam desenvolver seus TCCs.

Portanto, implantou-se uma alteração na segunda atividade da disciplina (atividade 2), que passou a ser composta por um pré-projeto de pesquisa a ser desenvolvido pelo estudante para utilização no desenvolvimento do TCC. A principal alteração nessa atividade 2 aconteceu para que pudesse dar uma oportunidade prática aos estudantes para que começassem a pensar no seu TCC, e mais ainda, para que pudessem incentivar os estudantes a utilizar os conceitos da disciplina e repensar sobre a importância da MC para o seu desenvolvimento.

Para mitigar as dúvidas e aumentar o nível de qualidade da atividade, aulas em vídeo foram postadas na disciplina com tópicos específicos sobre as etapas de construção de um trabalho científico, além do aumento no número de encontros síncronos (aulas online).

\subsection{Metodologia e Apresentação dos Resultados}

Para esse estudo utilizou-se uma base de dados obtida de uma IES privada. A base de dados é composta de duas avaliações: notas na disciplina de metodologia científica cursada nos anos de 2016 e 2017; e notas de aprovação dos estudantes quando matriculados na disciplina TCC.

Com relação à disciplina $\mathrm{MC}$, fez-se um estudo analítico e indutivo com os dados de aprovação dos estudantes nessa disciplina para os anos 2016 e 2017. Para essa análise, considerou-se o aproveitamento máximo na disciplina, quando os estudantes atingiram a nota de aprovação igual ou superior a 9,0 (nove) e quando há aprovação com a nota máxima de 3,0 (três) na atividade 2, que é a atividade de construção do préprojeto de pesquisa.

Com relação ao TCC, foi realizado um estudo comparativo sobre o desempenho dos estudantes aprovados na finalização desse trabalho entre os anos de 2016 e 2017, realizando uma análise das notas de aprovações e considerando o critério de aproveitamento máximo quando há aprovação final no TCC com nota igual ou superior a 9,0 (nove).

A partir dos dados levantados e analisados das notas de aprovações dos estudantes em cada ano, foi levantado o resultado obtido no desempenho das notas e o percentual de melhoria dos resultados, depois que foi realizada a alteração na atividade 2 no ano de 2017. 
A Tabela 1 apresenta os dados coletados e analisados para a disciplina de metodologia científica e para o TCC.

Tabela 1: Dados coletados e analisados no estudo, dos anos 2016 e 2017

\begin{tabular}{c|c|c|c|c|c|c} 
& \multicolumn{3}{|c|}{ DISCIPLINA METODOLOGIA } & \multicolumn{3}{c}{ TCC } \\
\hline $\mathbf{A N O}$ & $\begin{array}{c}\text { Total de } \\
\text { estudantes } \\
\text { matriculados }\end{array}$ & $\begin{array}{c}\text { Aproveitame } \\
\text { nto máximo } \\
\text { na Atividade } \\
2 \text { (nota 3,0) }\end{array}$ & $\begin{array}{c}\text { Percentu } \\
\text { al }\end{array}$ & $\begin{array}{c}\text { Total de } \\
\text { estudantes } \\
\text { matriculados }\end{array}$ & $\begin{array}{c}\text { Aproveitame } \\
\text { nto máximo } \\
\text { no TCC (nota } \\
\text { acima de 9,0) }\end{array}$ & $\begin{array}{c}\text { Percentu } \\
\text { al }\end{array}$ \\
\hline $\mathbf{2 0 1 6}$ & 1333 & 747 & $56,0 \%$ & 1148 & 158 & $13,7 \%$ \\
\hline $\mathbf{2 0 1 7}$ & 1925 & 1601 & $83,2 \%$ & 906 & 647 & $71,4 \%$ \\
\hline
\end{tabular}

Fonte: Instituição de Ensino Superior privada

Com relação à disciplina MC, de uma população de 1333 estudantes matriculados em 2016, 1174 foram aprovados. Desses aprovados, 747 estudantes (56\%) conseguiram atingir o aproveitamento máximo na atividade 2 (pré-projeto de pesquisa), ou seja, obtiveram nota máxima 3,0 (três). Observou-se que 427 (36,4\%) estudantes não obtiveram a nota máxima ou não realizaram essa atividade 2.

Observando os dados da disciplina TCC, em 2016, foram identificados 1148 estudantes matriculados nessa disciplina. O total de aprovados foi de $774(67,4 \%)$ estudantes e desses, apenas 158 concluíram com aproveitamento máximo (nota igual ou superior a 9,0) no TCC.

Com respeito ao desempenho dos estudantes matriculados em 2017, do universo de 1925 estudantes da disciplina de metodologia científica, 1783 (92,6\%) foram aprovados. Desses aprovados, 1601 (83,2\%) estudantes atingiram o aproveitamento máximo na atividade 2 e somente $0,7 \%$ não finalizaram a Atividade 2.

Com relação ao TCC em 2017, do total de 906 estudantes matriculados nessa disciplina, 887 (97,9\%) foram aprovados e desses, 647 (73\%) estudantes atingiram 0 aproveitamento máximo com nota igual ou superior a 9,0 (nove) e 240 (27\%) não tiveram aproveitamento máximo no TCC.

Para verificar o desempenho discente nas duas disciplinas consecutivas, e realizar uma comparação entre o desempenho obtido na disciplina MC e na disciplina TCC foram realizadas observações em duas amostras específicas de estudantes aprovados que cursaram tanto a disciplina metodologia quanto o TCC, sequencialmente. 
Amostra 1: foi analisada uma amostra de 48 estudantes matriculados no TCC em 2016. Desse total, somente $06(12,5 \%)$ estudantes que realizaram o TCC tiveram aproveitamento máximo (nota superior a 9,0). Desses mesmos 48 estudantes matriculados, somente $13(27 \%)$ haviam sido aprovados com aproveitamento máximo na disciplina de metodologia científica e 11 (23\%) não realizaram ou não atingiram nota máxima na atividade 2 , quando realizada.

Amostra 2: observados os estudantes que cursaram e foram aprovados na disciplina MC no primeiro semestre de 2017 e que realizaram o TCC no semestre seguinte (2017.2). A partir de uma amostra de 221 estudantes que se encaixaram nesse perfil, 151 (68,4\%) alcançaram nota superior a 9,0 (nove) e 70 (31,6\%) estudantes não atingiram o aproveitamento máximo no TCC.

Para efeitos de comparação de desempenho, verificou-se que desses 70 estudantes que não alcançaram aproveitamento máximo no TCC em 2017, 57 estudantes também não obtiveram aproveitamento máximo na disciplina metodologia científica. Além disso, identificou-se que apenas 10 estudantes não atingiram nota máxima ou não realizaram a atividade 2 (pré-projeto de pesquisa).

\section{Discussão sobre aproveitamento do estudo e Implicações no desenvolvimento do Trabalho de Conclusão de Curso}

Após a docência por dois anos consecutivos na disciplina Metodologia Científica, em cursos de pós-graduação 100\% online em IES privada, o relato dessa experiência com alteração na disciplina MC, que influenciou na melhoria da qualidade dos trabalhos e na aprovação com aproveitamento máximo dos estudantes, foi importante para averiguar a melhoria na qualidade da implantação da atividade de pesquisa em que os estudantes definem seus pré-projetos de pesquisa. Esses pré-projetos podem ser utilizados pelos estudantes para iniciar suas pesquisas para construção do TCC. Nos pré-projetos são apresentados o tema escolhido, problema-tema, a justificativa, objetivos, cronograma de desenvolvimento e referências bibliográficas iniciais da pesquisa. Também foi fundamental para definir o aumento do número de encontro com os estudantes (aulas síncronas online) para dar-Ihes mais confiança no desenvolvimento da atividade.

Verificou-se ao final que a maioria dos estudantes desconhecia as normas envolvidas na elaboração de textos científicos, tais como: desenvolvimento e estrutura de um trabalho científico, procedimentos para se fazer pesquisas bibliográficas, citações diretas e indiretas; e essa deficiência prejudicava a qualidade do trabalho final para conclusão do curso, precisando ser melhorada com a orientação do professor na disciplina TCC. 


\section{Considerações Finais}

Diante de todas as afirmações aqui colocadas, entende-se o porquê da presença da disciplina de metodologia científica nos currículos dos cursos de pós-graduação. $O$ exercício da pesquisa leva o estudante a adquirir hábitos que poderão ser utilizados nos trabalhos acadêmicos-científicos ou nas apresentações profissionais no ambiente empresarial.

O principal objetivo de discutir sobre as implicações da formação deficiente nessa disciplina, especialmente para o desenvolvimento do trabalho de conclusão de curso (TCC) foi atingido. Foi confirmado o impacto positivo no resultado de aprovação dos estudantes que cursaram a disciplina metodologia científica com a atividade 2 alterada para a construção do pré-projeto de pesquisa. Devido às alterações aplicadas no formato da atividade avaliativa 2 da disciplina, ficou evidente o aumento no percentual de aprovação e aproveitamento máximo dos estudantes na disciplina de TCC.

Espera-se que a discussão a partir desse estudo, alavanque a necessidade de melhorias na estrutura de oferta da disciplina metodologia científica para os cursos de pós-graduação online, principalmente visando a abordagem de pesquisa científica. Este estudo também visa dar ênfase na necessidade de aumento da qualidade dos trabalhos de conclusão de curso e no maior interesse dos professores que atuam como orientadores de TCC nesta modalidade de ensino, para o maior uso de técnicas de metodologia científica.

\section{Referências Bibliográficas}

LEITE, Flávia R. P. e ANDRADE, José R. (2015). A metodologia científica na universidade: o que estudantes do ensino superior acham da disciplina de metodologia científica. REBES (Pombal - PB, Brasil), v. 5, n. 1, p. 63-74, jan.-mar., 2015 ISSN 2358-2391. - Disponível em <http://www.gvaa.com.br/revista/index.php/REBES/article/view/3156/2651>.

\footnotetext{
MAIA, Rosane Tolentino (2008). A importância da disciplina de metodologia científica no desenvolvimento de produções acadêmicas de qualidade no nível superior. Departamento de Ciências Sociais - Universidade Estadual de Maringá (DCS/UEM). Revista Urutágua - revista acadêmica multidisciplinar. n 14. Mar 2008. Maringá - Paraná - Brasil - ISSN 1519.6178. Disponível em: $<$ http://www.urutagua.uem.br/014/14maia.htm>.
} 
MEC, Ministério da Educação. Referenciais de qualidade para os cursos a distância. Brasília, fevereiro de 2012. Disponível em . Acesso em 22 de fevereiro de 2012.

OLAF, Zawacki Richter; TERRY, Anderson. Educação a distância online: construindo uma agenda de pesquisa. 1ª edição. São Paulo: Artesanato Educacional, 2015.

OLIVEIRA, Tamires A. B. e VALENÇA, Kleber F. P. (2015). A importância da metodologia Científica para o Ensino e Aprendizagem no Ensino Superior. Anais do XII Congresso Nacional de Educação - EDUCERE. Disponível em .

SEVERINO, Antônio Joaquim. Metodologia do trabalho científico. 21 ed. São Paulo: Cortez, 2000. 